\title{
El sistema de crédito digital para microempresarios en Colombia
}

\author{
Lenin Alonso Muñoz Giraldo*
}

\author{
Recibido: 10 de agosto de 2020 \\ Revisado: 15 de septiembre de 2020 \\ Aprobado: 10 de octubre de 2020
}

Citar como:

Lenin Alonso, M. G. (2021). El sistema de crédito digital para microempresarios en Colombia. Revista CIFE, 23(38). https://doi.org/10.15332/22484914.6131

\section{Resumen}

El proyecto aplicado empresarial denominado 'ABI-Microcréditos' es un emprendimiento en el sector fintech colombiano. Tiene como base la economía colaborativa y busca constituirse en una estrategia sostenible frente a los sistemas de crédito informal. Se plantea, además, como solución a las necesidades y requerimientos de crédito para la inversión en capital de trabajo de microempresarios, y como un esquema seguro y rentable de apoyo al desarrollo empresarial con base en un gran componente tecnológico y social. Para el presente proyecto se empleó, como principal metodología de diseño, modelación y descubrimiento, el design thinking; igualmente, se recurrió a herramientas como el Value Proposition Canvas, para depurar la estrategia de valor, y el buyer persona, para definir el arquetipo de lo que se consideraría como cliente del servicio. A partir de la implementación de estas metodologías y del proceso de empatizar con el problema, el usuario y la competencia, se configuró la solución ABIMicrocréditos. Finalmente, se modelaron los principales supuestos del mercado y el impacto de estos sobre el comportamiento financiero del negocio, identificando los principales factores de sensibilidad de la situación financiera y el flujo de caja esperado del proyecto.

Palabras clave: microcrédito, tasa de interés, microempresa, fintech, aplicación móvil, design thinking, emprendimiento.

Clasificación JEL: D14, E26, G2, G29, O16.

\footnotetext{
* Universidad del Rosario, Escuela de Administración, Bogotá, Colombia; Universidad del Cauca, Facultad de Ciencias Agrarias, Popayán, Colombia. ORCID: https://orcid.org/0000-0002-6537-245X. Correo electrónico: lemunoz@unicauca.edu.co
} 


\title{
The digital credit system for micro-entrepreneurs in Colombia
}

\begin{abstract}
The Applied Business Project called 'ABI-Microcredits' is a venture in the Colombian fintech sector based on the collaborative economy and which seeks to become a sustainable strategy against informal credit systems. It is also proposed as a solution to the credit needs and requirements for investment in working capital of micro-entrepreneurs, and as a safe and profitable scheme to support business development based on a large technological and social component. For this project, Design Thinking was used as the main methodology for the design, modeling and discovery of the solution; likewise tools such as the Value Proposition Canvas were used to refine the value strategy and the Buyer Persona to define the archetype of what would be considered as a customer of the service. Based on the implementation of these methodologies and the process of empathizing with the problem, the user and the competition, the ABI-Microcredits solution was designed. Finally, the main market assumptions and their impact on financial behavior of the business were modeled, identifying the main sensitivity factors of the financial situation and the expected cash flow of the project.
\end{abstract}

Keywords: microcredit; interest rate; micro-enterprise; fintech; mobile app, Design Thinking, entrepreneurship.

JEL Classification System: D14; E26; G2; G29; O16.

\section{Introducción}

ABI-Microcréditos es un emprendimiento en el sector fintech colombiano; tiene como base la economía colaborativa y busca consolidarse como una estrategia sostenible contra los sistemas de crédito informal, así como como solución a las necesidades y requerimientos de crédito para la inversión en capital de trabajo de microempresarios, y como un esquema seguro y rentable de apoyo al desarrollo empresarial con base en un gran componente tecnológico y social.

En ABI se dispondrá de una plataforma web/app que permitirá conectar a los microempresarios - que requieren créditos para invertir en sus negocios- con entidades y fondos de financiación, así como con programas de créditos disponibles. La compañía ofrece una validación de los clientes (microempresarios demandantes de créditos) y de los riesgos, además hace el arbitraje de las transacciones desarrolladas a través de nuestro sistema. Nuestro producto consiste en una plataforma de evaluación, validación, gestión y administración de créditos entre microempresarios y fondos de inversión y financiación pública y/o privada. La compañía busca consolidarse en el mercado de las fintech en Colombia y convertirse en una alternativa sólida y sostenible que permita al mercado de créditos y a las autoridades luchar contra los sistemas o modelos ilegales de crédito y los altísimos costos sociales y económicos asociados a esta práctica. Igualmente, ABI busca 
consolidarse como un sistema eficiente de inclusión financiera y crediticia para los microempresarios que requieren de manera constante flujos de efectivo para financiar sus operaciones.

\section{Oportunidad de mercado}

Según el artículo publicado en el portal web Finanzas Personales, Guerrero (2019) estima que en Colombia más del $50 \%$ de los hogares han acudido a sistemas informales de crédito; además, plantea que, según cálculos realizados, los colombianos les adeudaban a los prestamistas informales cerca de $\$ 5$ billones en ese momento. De igual forma, en la Encuesta de Mercado de Crédito Informal en Colombia, citado por El Tiempo (2015) y el Estudio de Demanda de Productos Financieros de la Superintendencia Financiera y la Banca de Oportunidades (2017), se estimó que el $66 \%$ de los microempresarios que solicitan el microcrédito lo hacen con el objetivo de financiar su actividad empresarial, es decir, tienen como motivo de endeudamiento acceder a recursos para capital de trabajo. Asimismo, y según cifras de Economía Aplicada (2019), para 2018 existían en Colombia cerca un millón seiscientos veinte mil empresas (personas naturales y jurídicas), de las cuales el 92,84\% correspondían a microempresas, contando con un universo de clientes potenciales bruto para ABI de negocio de más de 1500000 usuarios. Se espera iniciar con una cobertura del 0,1\% de ese mercado e ir creciendo paulatinamente hasta llegar al $10 \%$ de los potenciales clientes

en 5 años, logrando así generar negocios por un valor superior a los \$604 000 millones e ingresos de más de $\$ 19000$ millones por intereses anuales al final del quinto año de operaciones.

Se hace evidente la necesidad de ofrecer alternativas de financiación a los microempresarios en Colombia, esto, por cuanto gran parte del crecimiento y desarrollo económico del país recae sobre estas iniciativas empresariales. Además, es imperativo luchar de manera frontal contra los sistemas de crédito informal que erosionan la economía y salud mental y social de las familias que caen en estos esquemas de ilegalidad crediticia. Parte de esta tarea puede consistir en implementar las herramientas digitales para asegurar la vinculación de clientes que hoy no son susceptibles de crédito por parte de la banca formal y tradicional; así mismo, como estrategia para la aplicación de soluciones innovadoras que disminuyan los trámites, los costos y las barreras para acceder a la formalidad crediticia. El proyecto de ABIMicrocréditos nace como una alternativa y una respuesta a estas necesidades imperiosas del sistema de financiación y como una apuesta social, sostenible e innovadora para las microempresas colombianas. 


\section{Descripción general del proyecto}

\section{Antecedentes}

Actualmente los microempresarios en Colombia, al igual que en la mayoría de los países de América Latina, tienen grandes necesidades de financiación de sus actividades comerciales y productivas. Pero ¿a dónde están acudiendo los colombianos a la hora de endeudarse? Según Hernández y Oviedo (2016), el $80 \%$ de los créditos son formales y el $20 \%$ informales, de los cuales el principal renglón de participación (42,8 \%) lo ocupa el prestamista o llamado "gota a gota". Estos investigadores definen a los prestamistas "gota a gota" como "personas naturales que otorgan créditos ilegales en un alto porcentaje, los cuales se institucionalizan entre quienes no pueden acceder a préstamos del sistema financiero" (Hernández y Oviedo, 2016, p. 142).

Al existir diversas barreras para el ingreso a los sistemas de crédito formal, las personas se ven obligadas a acudir a estos modelos informales, lo que les acarrea altos costos, estrés y dependencia al circuito de créditos informales, creando un círculo vicioso que incrementa de manera exponencial las deudas del acreedor y lleva a la quiebra, o incluso a tomar decisiones fatales, a los pequeños empresarios que han caído en las redes de prestamistas ilegales.

Los actuales modelos de calificación crediticia, la poca capacidad operativa para gestionar las solicitudes en tiempos mínimos, la periodicidad de las cuotas y el papeleo, son algunas de las causas que Asobancaria señala como principales motivos para que las personas opten por acudir a los créditos informales.

En el caso de las microempresas, el Estudio de Demanda de Inclusión Financiera, de la Superintendencia Financiera y la Banca de Oportunidades (2017), señaló que el 65,5\% de las microempresas no tiene ningún tipo de crédito y que el 79,4\% no tiene acceso a créditos formales. El mismo estudio señala que, en su mayoría, el uso que el microempresario le da al crédito se encuentra principalmente orientado al capital de trabajo (entre el $39 \%$ y el $60 \%$, dependiendo de la fuente del crédito).

La producción de un país depende, en gran medida, de los capitales disponibles para la inversión en los negocios, esto significa que la disponibilidad de recursos para financiar la operación y producción a partir del acceso al crédito es un tema fundamental para planear y asegurar el crecimiento económico de una nación. En nuestro caso, la relación inversión-crédito-crecimiento no es ajena; Colombia debe prestarle mayor atención y continuar la senda del apoyo a la inclusión financiera como estrategia transversal de desarrollo y crecimiento económico apalancado en la inversión.

Además de la innegable necesidad del crédito como pulmón de la inversión, el desarrollo de un sistema de inclusión financiera basado en modelos eficientes y justos, que aseguren no solo el crecimiento del empresario, sino también del ecosistema, se configura como una 
estrategia de lucha frontal contra los modelos ilegales de crédito. Estos créditos ilegales le han acarreado a la economía y a la sociedad colombiana grandes pérdidas a nivel financiero, empresarial y familiar, incluso han generado la irreparable pérdida de vidas humanas.

Una de esas irreparables pérdidas la registró la $\mathrm{BBC}$, que en un reportaje del 7 de febrero de 2019 informaba el fatal desenlace de una mujer en Ibagué. En su crónica escribieron: "Se llamaba Paola Moreno Cruz. Tenía solo 32 años, pero desesperada por la presión de no poder devolver un crédito con hasta un 40 \% de interés se lanzó al vacío" (BBC Mundo News, 2019).

Paola es una de las tantas víctimas de este perverso modelo que camufla recursos ilícitos y condena a las personas a un calvario de pagos incesantes, ilegales y usureros, que los pone al borde de la debacle psicológica y los expone a un estrés del que pocos salen ilesos.

Esta apuesta por un sistema de crédito ágil, eficiente, cercano a las necesidades de las personas y las empresas, con una valoración de riesgo diferencial, que le abre paso a la formalidad a miles de colombianos y colombianas que hoy piden lugar en la inclusión financiera, es también una estrategia por la salud financiera de nuestra economía y nuestros microempresarios, una estrategia para la salud física, emocional y psicológica de los ciudadanos que hoy requieren de una solución ajustada a sus requerimientos, necesidades y potencialidades que se encuentren a tono con la nueva era.

\section{Misión}

ABI es la solución sostenible y socialmente responsable de microcréditos, que pretende poner a disposición de los microempresarios créditos para capital de trabajo, consolidándose como una alternativa legal y a precios justos que apoye el crecimiento de este sector de la economía.

\section{Metas y objetivos}

- Ser la mayor y más grande plataforma de microcréditos para microempresarios y el sistema colaborativo más eficiente para fondos de inversión, empresarios y la sociedad colombiana.

- Consolidar a ABI como la mejor alternativa de lucha contra el crédito informal en el sector de las microempresas.

- Obtener el reconocimiento de efectividad y eficiencia por parte de nuestros clientes (demandantes y oferentes de créditos) a nivel nacional.

- Establecer un modelo y esquema de negocio de microcréditos que sea seguro, rentable y sostenible. 
- Lograr atender el $40 \%$ de los microcréditos del sector microempresas en Colombia, llegando a posicional al quinto año un mínimo de $\$ 604000$ millones anuales en créditos.

\section{Mercado objetivo}

Demandantes de créditos: microempresarios familiares, personas naturales o jurídicas, con establecimiento de comercio reconocido, número de celular a su nombre y cuenta bancaria que requieren microcréditos para satisfacer necesidades puntuales de inversión en capital de trabajo y crecimiento o expansión de sus negocios.

\section{Industria o sector del negocio}

La industria financiera y crediticia ha visto nacer una nueva rama en su quehacer, el cual tiene como origen la unión de las capacidades tecnológicas y las necesidades del sector financiero. Esta unión ha generado el sector de las fintech, el cual conforma una industria en desarrollo y crecimiento en Colombia y el mundo. ABI nace en el seno de esta industria y se fortalece con los valores de la economía colaborativa. Al ser este sector una industria en crecimiento, las oportunidades actuales son abundantes y los nichos de mercado son amplios. El sector fintech en Colombia ha venido ganando espacios y reconocimiento, abriendo nuevos mercados y creciendo en organización con la Asociación Colombia Fintech, entidad que canaliza los esfuerzos, experiencias y oportunidades para el sector, convirtiéndose en un aliado clave del presente proyecto y factor fundamental para el aprovechamiento de los grandes cambios que, en materia crediticia, financiera y de acceso al sistema bancario, se avecinan para Colombia y Latinoamérica.

Según Bahamón (2017), citando el portal Finnovista, el sector fintech en Colombia presenta algunas subdivisiones entre las cuales se pueden incluir: seguros, pagos y remesas, trading y mercados, educación financiera y de ahorro, crowdfunding, préstamos en línea, gestión de finanzas personales, entre otros. La autora refiere que el segmento de pagos y remesas es el más grande entre los subsectores, y que, junto con préstamos en línea, gestión de finanzas empresariales y calificación, identidad y fraudes agrupan el $63 \%$ de todas las compañías en el sector fintech en Colombia.

Dentro de los actores del subsector préstamos en línea, miembros del ecosistema fintech en Colombia, se han podido identificar empresas como Aflore, Lineru, Rapicredit, Prestarápido, Fintu, Kredicity, Finaktiva, entre otras, sumando cerca de 31 organizaciones constituidas legalmente en el mercado. Sin embargo, y este es uno de los elementos que se desarrollan en la presente propuesta, se considera que el principal foco de crecimiento de soluciones presentadas por el subsector del crédito en línea es el de créditos personales, existiendo algunas soluciones para pequeñas empresas, donde los montos y requisitos solicitados sobrepasan las capacidades del segmento que se quiere atacar con ABI. Tal es el caso de Finaktiva, quienes generan créditos para capital de trabajo, pero se enfocan en pequeñas 
empresas y sus rangos de crédito exceden, por cientos, los montos requeridos por el sector microempresarial que desde nuestra solución se pretende abordar.

Por otro lado, cabe anotar que el sector fintech se encuentra en franco crecimiento, no solo en Colombia, sino también a nivel mundial, y así lo señalan desde el Finance \& Investment Club de la Universidad de los Andes y, en particular, Avendaño (2019), quien se refiere al crecimiento del sector al plantear que los fondos destinados a empresas fintech durante el último año en algunos lugares han llegado a duplicarse, y en el caso latinoamericano, en particular, esos fondos han pasado de 30 a 54 billones, lo que permite inferir el desarrollo y crecimiento del sector.

\section{Validación de la oportunidad}

\section{Descubrimiento de la oportunidad}

El proceso de descubrimiento de la oportunidad se originó en la observación de una problemática latente en nuestra sociedad: los efectos del crédito informal, el llamado "gota a gota". Diversos reportajes, noticias y artículos dieron señales de la importancia que ese tema venía teniendo en la sociedad colombiana. Igualmente, la generación de políticas y lineamientos del Gobierno central en torno a la necesidad de inclusión financiera, dieron claras señales de la tendencia que el mercado estaba exigiendo, al menos en términos legales, en torno a los servicios financieros.

Es así como a partir del interés personal, se inició la indagación con entrevistas semiestructuradas de las causas del crédito informal. Se visitaron diversas personas que aseguraban haber adquirido estos servicios y se identificaron tres causas como las principales razones referidas: el consumo (30\%), atender una emergencia (25\%), y financiar necesidades de capital de trabajo (35\%). Fue así como se decidió indagar con mayor detalle en las personas que referían la financiación de capital de trabajo para sus pequeños negocios.

A partir de estos hallazgos preliminares se identificó y definió el problema central, el cual consiste en que "los microempresarios colombianos no tienen acceso a sistemas formales de crédito para financiar su capital de trabajo, lo que les obliga a acudir a modelos informales de crédito o también llamados gota a gota".

Posteriormente, se realizaron varios procesos de empatía con el posible cliente. El primero consistió en la observación y el desarrollo de conversaciones con los microempresarios, a partir de estas se construyó un mapa de empatía del cliente, donde se detallan los elementos más relevantes de su comportamiento, lo que es importante para él y aquello que le genera temor.

Luego del proceso de empatizar con el prospecto de cliente, se desarrolló un ejercicio de observación activa, que consistió en acceder a un crédito informal para conocer el proceso, 
definir los requisitos y el modelo de validación de la información, así como el proceso de cobro. Fue de este modo como se eligió una de las casas de créditos más conocidas en la ciudad de Popayán (Cauca), denominada "Prestamos al Instante", que contacta a sus clientes por medio de volantes repartidos a las afueras de bancos o pegados en postes de energía, y ofrecen préstamos desde $\$ 200000$ y entrega del recurso en un día, sin fiador o codeudor, solo exigen un pago del $10 \%$ de interés que, en la práctica, es mucho mayor, debido a su liquidación diaria y al cobro de intereses sobre intereses. Trabaja con pagos diarios y, en montos altos y con clientes acreditados, ofrecen cobrar semanalmente. A partir de ello, se construyó lo que se denominó la ruta del crédito informal, el cual muestra el proceso general del crédito informal desde el contacto inicial hasta el último pago, que normalmente viene acompañado del ofrecimiento de un nuevo crédito por mayor monto que el anterior.

Por último, se construyó una historia de un personaje ficticio y el camino que recorre tratando de buscar financiación para su negocio, hasta llegar a manos del prestamista informal e iniciar su descenso al camino de la angustia. Esta historia se graficó y compartió con un público al cual se preguntó sobre su percepción del problema, si había comprendido y si identificaba los principales agentes en la situación problemática descrita. De esta actividad, se lograron identificar cinco actores con roles definidos en el problema: cliente, banco, prestamista, cobrador y familia. Así como los momentos claves y las situaciones que significaron un punto de quiebre en la historia, lo que brindó elementos para el diseño de la solución y la conformación de la propuesta de valor.

\section{Actores identificados en la cadena causal del crédito informal}

Cliente: persona, dueño de una microempresa que requiere de forma frecuente recursos para financiar el capital de trabajo de su negocio.

Banco: entidad legalmente constituida y reconocida que pone al público una oferta de créditos, para lo cual exige el cumplimiento de unos requisitos específicos.

Prestamista: persona difícil de identificar, a veces se suele presentar como una organización o empresa, quien cuenta con capitales disponibles para poner a disposición del público créditos con montos desde los \$200 000 hasta los \$2 000000 , usualmente. El origen de sus fondos no siempre es claro y emplea a terceros para asignar y cobrar los créditos.

Cobrador: persona que trabaja para el prestamista y se encarga de entregar los montos prestados y realizar las tareas de cobro y recepción de cuotas diarias.

Familia: agentes externos al problema, pero que se ven afectados por el mismo. Su rol es de compañía y apoyo al cliente. El sustento de la familia depende, en gran medida, de los resultados del negocio del cliente. 
A partir de los hallazgos, y realizando un análisis de las molestias referidas respecto a las acciones desarrolladas por el potencial cliente cuando requiere de recursos para financiar sus necesidades de capital de trabajo, se planteó una propuesta de valor a partir de la metodología del Value Proposition Canvas, el cual se convirtió en la guía de diseño de la solución que sería validada.

Los principales elementos que se identificaron en el proceso de empatía y conocimiento del problema son:

- Los microempresarios no tienen amplio conocimiento financiero ni tampoco una cultura financiera.

- Consideran que los procesos de legalización de la empresa son trámites costosos y al final innecesarios.

- Están dispuestos a pagar intereses altos con tal de obtener el crédito.

- Quienes necesitan con mayor frecuencia el crédito son aquellos que presentan una menor cartera vencida.

- El cliente valora su línea de crédito formal o informal.

- En el caso de los créditos informales, el cliente valora no tener que desplazarse para realizar los pagos y reconoce que los cobradores son discretos.

- Normalmente no les cuentan a sus familias sobre sus créditos.

El insight identificado fue: "Un negocio bien administrado, da para que coma la familia y el gota a gota".

En el segmento de mercado seleccionado el Buyer Persona se caracteriza por ser una persona de familia, microempresario, sin acceso al crédito formal, para quien su nombre y reputación es importante. Requiere constantemente de recursos para poder financiar su operación, teme perder su negocio. Su familia y su negocio son aspectos muy importantes en su vida y son igualmente motivo de orgullo. La familia es la razón por la que se levanta cada día a trabajar. Teniendo como base los elementos identificados, se creó un primer prototipo de la solución diseñada, que consistía en ofrecer de manera personal, a algunos clientes potenciales, créditos a tasa de interés legal y sin la exigencia de mayores requisitos. Se logró identificar el interés de los empresarios en sistemas de crédito a menor costo, sin embargo, en un principio se mostraron displicentes e incrédulos ante la oferta de un sistema formal de crédito que operara fuera de los paradigmas de las entidades crediticias tradicionales. La validación arrojó un especial reconocimiento a la disminución de los costos y al sistema de beneficios por el buen manejo del crédito. 
Este esquema tiene como principal reto su escalabilidad, respuesta rápida a la solicitud de crédito y gestión eficiente de cada uno de los clientes; se estima que estos elementos terminarán incrementando los costos de operación del sistema. Se define un segundo prototipo a partir de un sistema de gestión digital de las solicitudes a partir de una aplicación móvil, para este caso se empleó un formulario en línea. Luego, se llevó este nuevo prototipo y se recopilaron las observaciones del cliente potencial.

Para esta segunda versión de la solución, las personas señalaron que su principal obstáculo es su escaso conocimiento sobre el registro y operación de plataformas virtuales, así como el manejo de aplicaciones. Sin embargo, resaltaron su fácil manejo y sencilla comprensión. Por otra parte, se deben resolver las cuestiones relacionadas con el acceso a internet.

En un periodo de 30 días se colocaron créditos por un monto de un millón setecientos mil pesos ( $\$ 1700$ 000), se midieron los tiempos de mora en los pagos, la tasa de conversión, el monto comúnmente solicitado y la retoma de créditos. Estos datos sirvieron como insumo para la simulación financiera y el afinamiento del modelo de servicio crediticio a ofertar.

Adicionalmente, se logró identificar el perfil de los Early Adopters, los cuales se caracterizan por ser empresarios más jóvenes ( 25 a 38 años) con negocios orientados, mayoritariamente, a los bienes y servicios digitales. Su principal característica es que tienen familias jóvenes y su acceso al mundo digital es mayor, refieren tener redes sociales y hacer uso frecuente y recurrente de las mismas. Así, a partir de las conversaciones sostenidas con diferentes clientes potenciales, se logró estimar que este tipo de empresario dedica más de 3 horas diarias en promedio a las redes sociales y que la principal dentro de estas es Facebook. De igual forma, estos adoptadores tempranos afirman conocer o haber escuchado de los nuevos modelos de inclusión financiera y las sinergias que se están presentando entre el sector financiero y tecnológico.

\section{Construcción y validación del mínimo producto viable}

Validación del mercado: Se diseñaron dos prototipos de la solución, el primero consistió en la oferta personal y directa de créditos a microempresarios. Se realizaron, en promedio, dos visitas por cada cliente potencial. En la primera visita se indagaba sobre el interés o necesidad de adquirir un microcrédito y se les presentó la oferta del sistema de microcréditos de ABI, la cual consiste en créditos a tasas legales y con una validación rápida de su elegibilidad, sin requisitos engorrosos ni exigencia de garantías o prendas. Después, se brindaba la información y se preguntaba sobre el interés en adquirir el crédito y el monto que podría requerir. A los clientes que afirmaban que iban a pensar la propuesta se les dejaba un número de contacto y se agenda una nueva cita. Se visitaron en principio 10 empresarios.

En la segunda visita ya se hacía énfasis en la intención de tomar o no el crédito y se presentaban las opciones de periodicidad de pagos existentes. Para esta ocasión, se visitaron 
5 clientes que pidieron la segunda cita y se pusieron en contacto para obtener mayor información. Al final, 7 personas tomaron el crédito, la tabla 1 muestra los valores de las variables del proceso de validación de la idea adelantando con estas y los respectivos créditos otorgados a cada una de ellas.

Tabla 1. Principales métricas de la validación

\begin{tabular}{|l|l|}
\hline Detalle de variable & \\
\hline Visitas realizadas & 10 \\
\hline Créditos otorgados & 7 \\
\hline Monto otorgado & $\$ 1700000$ \\
\hline Días de mora total & 3 \\
\hline Tasa de interés & $3 \%$ MV $(42,5 \% \mathrm{EA})$ \\
\hline Periodicidad de cuota & Semanal \\
\hline Número de cuotas & 4 \\
\hline
\end{tabular}

Nota: se presentan los valores de las variables del proceso de validación de la idea adelantando con 7 personas y los respectivos créditos otorgados a cada una de ellas.

Cabe señalar que la Superintendencia Financiera de Colombia, mediante un comunicado de prensa dio a conocer la Resolución No. 0829 del 28 de junio de 2019, en la cual certificaba que la tasa de interés máxima para microcréditos en el periodo 1 de julio a 30 de septiembre de ese año sería de 55,14 \% EA. Valor muy por debajo de cobrado en la validación realizada $(42,57 \%$ EA).

Continuando con la recopilación de información y la validación del modelo propuesto, se prosiguió con posterioridad a diligenciar una ficha de trabajo de campo por cada visita, donde se registraron los principales hallazgos y los comentarios más relevantes de cada uno de los potenciales clientes. Esta información fue fundamental para la construcción de la propuesta del valor y el diseño del segundo prototipo.

Las principales hipótesis validadas con este primer prototipo indicaron que los empresarios con establecimiento de comercio tienen mejor receptividad y un mejor manejo de cartera. Tener un negocio acreditado disminuye el riesgo de no pago o de cartera vencida, y la referencia de sus vecinos es un buen indicador de su acreditación y tiempo de labor. 
En la siguiente fase de validación se desarrolló un prototipo de la aplicación y se indagó con un grupo focal elementos de usabilidad, comprensión y manejo de la herramienta móvil. A partir de ello, se inicia la definición del modelo de contacto y de interacción con los clientes.

A partir del trabajo de validación se definieron nuevos elementos del modelo de negocio, el cual tendría una primera fase con agentes comerciales que visitarán a los clientes, apoyando la descarga y configuración del perfil del empresario por primera vez.

\section{Mínimo producto viable}

El proyecto inicia con visitas presenciales a potenciales clientes ofreciendo el servicio de microcrédito de ABI. El agente contó con un aplicativo en línea para diligenciar los datos del comercio y el empresario, tomar la fotografía del cliente y su negocio, del documento de identidad y registrar el monto solicitado, este aplicativo se encuentra en el vínculo al cual, y como parte del proceso de validación de identidad, se debe acceder desde una cuenta de Google. Otra herramienta en línea (hoja en Excel) liquidaría el plan de pagos automáticamente y se le compartiría al cliente.

Los pagos se recibirían por convenio de recaudo con Su Red, empresa contratada para este servicio, cuya escalabilidad sería evaluada.

Se planeó validar este nuevo nivel de la solución a partir del apalancamiento financiero que se estaba gestando con socios inversionistas con quienes se avanzaba en negociaciones. La validación consistía en contratar, por 15 días, un grupo de 5 agentes comerciales con un smartphone y acceso a internet para diligenciar los aplicativos en línea. Se programó colocar $\$ 10$ millones en microcréditos en esos 15 días.

\section{Producto o servicio}

\section{Descripción del producto o servicio}

$\mathrm{ABI}$ es un servicio de gestión de microcréditos para microempresarios que requieren de financiamiento de capital de trabajo e inversiones de ampliación de su negocio, este sistema funcionará sobre una aplicación móvil.

El sistema ABI gestiona, evalúa, recuerda pagos, entrega un balance de cuenta al cliente y registra usuarios y solicitudes. Gracias a la información suministrada por el cliente, es aplicando un esquema de valoración de riesgo diferenciado, el cual permite validar la viabilidad del crédito para ese empresario. Esta evaluación tomará menos de una hora y posteriormente se notificará la asignación del crédito procediendo a su desembolso en un lapso inferior a las 24 horas. Todo el proceso es virtual y no requiere de trámites presenciales del cliente. La firma de garantías es digital y el desembolso se realizará a una tarjeta débito. El diagrama de flujo de proceso de la solución ABI, puede ser consultado en el Anexo A. 
$\mathrm{ABI}$ es un sistema que se enfoca en los microempresarios y se convierte en una poderosa alternativa para la lucha frontal contra el crédito informal. Al tener una valoración de riesgo diferenciada, se asegura la inclusión de personas y negocios que no cuenten con experiencia crediticia, y que el sistema financiero tradicional no logre absorber. Por otro lado, se cuenta con tasas de interés mucho más bajas que las del crédito informal, atención 24/7 y no tiene costos ocultos ni cargos básico para los clientes.

\section{Plan de marketing}

Entorno económico: estimaciones del comportamiento de la demanda de créditos informales en Colombia han establecido que diariamente se tranzan cerca de \$2500 millones en estos los sistemas de crédito informal o ilegal (Forero, 2019). En promedio, estos créditos son otorgados a tasas del $10 \% \mathrm{MV}$ y sus principales usuarios son personas de estrato 1, 2 y 3 .

La Encuesta de Mercado de Crédito Informal en Colombia, y el Estudio de demanda de productos financieros de la Superintendencia Financiera y la Banca de Oportunidades (2017), estimaron que el $66 \%$ de los microempresarios que solicitan el microcrédito lo realizan con el objetivo de financiar su actividad empresarial, es decir, tienen como motivo de endeudamiento acceder a recursos para capital de trabajo. Igualmente, y según cifras de Economía Aplicada, para 2018 existían en Colombia cerca de 1620342 empresas (personas naturales y jurídicas) de las cuales el 92,84 \% corresponden a microempresas, contando con un mercado potencial para ABI de cerca de 1500000 usuarios. Según Hernández y Oviedo (2016), el $80 \%$ de los créditos en Colombia son formales y el $20 \%$ informales; de estos últimos, el principal renglón de participación (42,8\%) lo ocupa el prestamista o también llamado "gota a gota".

En el caso de las microempresas, el Estudio de Demanda de Inclusión Financiera de la Superintendencia Financiera y la Banca de Oportunidades (2017) señaló que el 65,5 \% de las microempresas no tiene ningún tipo de crédito, y que el 79,4\% (cerca de 1200000 microempresas) no tiene acceso a créditos formales. El mismo estudio señala que, en su mayoría, el uso que el microempresario le da al crédito se encuentra orientado al capital de trabajo (entre el $39 \%$ y el $60 \%$, dependiendo de la fuente del crédito).

Teniendo en cuenta las características del mercado, se planea iniciar con una cobertura del $0,1 \%$ de ese mercado potencial e ir creciendo paulatinamente hasta llegar al $16 \%$ de los clientes potenciales en 5 años (240 000 microempresarios). Se generarán negocios por un valor superior a los \$288 000 millones, ingresos para ABI de más de \$9216 millones por intereses anuales, al final del quinto año.

- Total Available Market (TAM): 1504325 microempresas

- Serviceable Available Market (SAM): 1053027 microempresas (70 \% del TAM) 
- Serviceable Obtainable Market (SOM): 600000 microempresas (57 \% del SAM)

\section{Tendencias en el mercado objetivo}

En la actualidad, los servicios fintech en Colombia vienen presentando un crecimiento acelerado según la Asociación Colombia Fintetch. En particular, el segmento de créditos digitales presenta un desarrollo del nicho de mercado que viene creciendo tanto en número de operadores como en capitales invertidos en estas líneas.

La implementación de nuevas tecnologías, como el internet de las cosas, y el uso masificado de blockchain permiten prever mayor eficiencia en estos sistemas y en los mecanismos de valoración del riesgo de los clientes, lo que, a la postre, repercutirá en una mayor capacidad de absorción en el mercado y la ampliación de los usuarios de estas soluciones.

El mercado se está concentrando hoy en día en los créditos digitales para consumo, y esta es la primera iniciativa que se enfoca en el apoyo y desarrollo de los microempresarios, al igual que le plantea una guerra frontal a los sistemas informales e ineficientes de crédito. Si bien existen otras alternativas en el mercado de los créditos en línea - las cuales se analizarán a profundidad más adelante-, la solución $\mathrm{ABI}$ es la única que se enfoca actualmente en los créditos de bajo monto, para que las microempresas financien sus pequeños requerimientos de capital de trabajo sin la exigencia de altos requisitos. La adopción de nuevas tecnologías, la oferta de dispositivos móviles más potentes y económicos, la ampliación en la cobertura de internet y la digitalización de los negocios, conforman el panorama perfecto para promover el desarrollo de estas iniciativas de gestión de crédito y la promoción de la inversión en el sector microempresarial de Colombia y Latinoamérica, así como la disminución del riesgo asignado a estos tipos de crédito, teniendo mayor acceso a información más fiable, oportuna y eficiente para la valoración y gestión de riesgos crediticios.

El servicio de ABI, al ser digital sobre una aplicación móvil, se prestará de manera directa teniendo aliados claves para la gestión y recepción de pagos, así como para la realización de depósitos.

Los clientes serán microempresas con una existencia previa mínima de doce meses; de propiedad de personas con edades entre 30 y 50 años (las cuales poseen una familia) con por lo menos un establecimiento de comercio. Serán negocios que requieran créditos de bajo monto para financiar capital de trabajo o inversiones de ampliación. Cabe aclarar que, si bien los adoptadores tempranos de la solución propuesta parecieran ser propietarios más jóvenes, es también cierto que la edad promedio de los dueños de microempresas acreditadas oscila entre los 38 y 50 años. Además, que el factor 'reputación' es uno de los más importantes dentro del algoritmo de calificación de riesgo que se ha creado para ABI, y el comportamiento de este factor incrementa con la edad, es decir, entre más adulto más le 
importa su reputación. Teniendo en cuenta estas consideraciones, se ha construido el siguiente segmento de mercado para ABI.

Perfil demográfico del propietario:

- Edad: 30 a 50 años

- Género: hombre / mujer

- Ubicación: ciudades capitales intermedias de departamento

- Nivel de ingresos: superior a 2 SMMLV

- Ocupación: trabajador independiente / propietario de negocio

- Educación: bachiller / técnico

Perfil de la empresa:

- Microempresa

- 12 meses de existencia previa mínima

- Con establecimiento de comercio

Se debe señalar que la línea de crédito que generará ABI es para microempresas, por eso el cliente, al final de cuentas, es la empresa y, por consiguiente, el modelo es un modelo business to business. No es una línea de crédito para consumo o personal, por ello se involucran dentro del target una serie de atributos deseados del negocio o la microempresa beneficiaria del crédito.

$\mathrm{B} 2 \mathrm{~B}$

Compra /

Adquisición

Costo / Precio

Marketing
El cliente acude a la solicitud de crédito para financiar su actividad, surtir su negocio o ampliar el mismo. Realiza la adquisición a partir de una necesidad claramente identificada por él.

Comparado con la principal opción actual, los modelos informales o "gota a gota", quienes cobran en promedio $10 \% \mathrm{MV}$, los costos asociados a los microcréditos otorgados por ABI son mucho menores; en promedio se pagarían tasas de interés mensual de entre el 2,8\% MV y el $3,8 \% \mathrm{MV}$

Sistema de inclusión financiera con valoración de riesgo diferencial.

Intereses por la financiación justos y más bajos respecto al modelo informal.

Autogestión del crédito.

Respuestas rápidas a las solicitudes (menor a una hora).

Disponibilidad 24/7.

Sin costos ocultos o cargos básicos.

Sin papeleos, codeudores o fiadores.

Esquema de reconocimiento de buen manejo crediticio 


\section{Análisis competitivo}

A partir de la Matriz de Análisis Competitivo (Anexo C), se puede concluir que ABI será la única plataforma de crédito en línea que se concentre en el desarrollo del sector microempresarial, con crédito de bajo monto para financiar capital de trabajo, lo que la convierte en pionera $\mathrm{y}$, seguramente, en el jugador más fuerte dentro de ese segmento. $\mathrm{Su}$ objetivo económico y social configura su segunda mayor fortaleza, debido a que no solo busca generar una rentabilidad económica de su negocio, sino que está aportando al desarrollo y crecimiento de los microempresarios, convirtiéndose en un aliado clave para la gestión de sus propios negocios.

Por otro lado, existen organizaciones que ya cuentan con un conocimiento y posicionamiento en el mercado de los créditos digitales, logrando llegar a diversos tipos de personas, incluyendo los microempresarios. Ser el nuevo operador en el mercado configura su mayor debilidad, e impone, de tajo, la necesidad imperiosa de posicionar claramente la propuesta de valor de ABI y su carácter de aliado clave para todos los microempresarios, como elemento diferenciador.

\section{Pronóstico de ventas}

Partiendo del escenario optimista de simulación de nuestro pronóstico de ventas (Anexo E), que tiene como principales variables una participación inicial del $0,1 \%$ en el mercado potencial global, un ticket promedio de crédito de $\$ 500000$ por cliente al mes y un estimado de tasa de interés del 3,2\% MV, se lograría tener un volumen de negocios por un valor de $\$ 625000000$ en créditos otorgados al mes, y unos 1250 clientes asistidos, llegando al final del año a 2138 solicitudes de crédito atendidas, gracias a una tasa de crecimiento de clientes del $5 \%$ mensual en ventas. Esa tasa de crecimiento de clientes incrementaría al $10 \%$ en el año 2 del proyecto, gracias al posicionamiento en el mercado dado por la estrategia comercial y las excelentes referencias de los clientes.

A partir de un escenario pesimista, que consiste en una participación del 0,007 \% del mercado total, lo que significa cerca de 100 solicitudes de clientes al mes y un ticket promedio de $\$ 300$ 000; al final del primer año se tendría una cartera de crédito de $\$ 44$ millones y 112 créditos atendidos en el último mes del primer año, con el supuesto de una tasa de crecimiento de clientes del $1 \%$ mensual. 


\section{Plan financiero}

\section{Flujos de caja}

Como se ilustró anteriormente, ABI requiere de inversiones iniciales del orden de los $\$ 58000$ 000, recursos destinados principalmente para el desarrollo y puesta en marcha de la aplicación móvil. Además de ello, se calcularon valores iniciales de costo de gestión de cliente por crédito en el primer año de \$14 564 — valor que disminuye con el paso los años-, y la adquisición de nuevos clientes, ítem que representa lo que le cuesta a la compañía gestionar el cliente y el crédito. Cabe anotar que dicho valor se presenta muy alto para el primer año, debido a la fuerza comercial y el impulso necesarios al principio de la operación, así como el supuesto moderado de número de clientes para el primer año $(0,01 \%$ del tamaño del mercado).

Para financiar los requerimientos iniciales de inversión y gastos de operación, se asumió el supuesto de adquisición de un crédito por $\$ 55000$ 000, pagadero a 24 cuotas mensuales y una tasa de interés del $15 \%$ EA. La tabla 2 muestra un resumen de la proyección del flujo de caja del plan a 5 años.

Tabla 2. Flujo de caja a 5 años

\begin{tabular}{|c|c|c|c|c|c|}
\hline Flujo de caja & Año 1 & Año 2 & Año 3 & Año 4 & Año 5 \\
\hline $\begin{array}{l}\text { Total ingresos por } \\
\text { ventas }\end{array}$ & $\$ 318.342 .530$ & $\$ 1.126 .530 .912$ & $\$ 6.445 .191 .348$ & $\$ 15.360 .000 .000$ & $\$ 19.353 .600 .000$ \\
\hline $\begin{array}{l}\text { Total egresos } \\
\text { operativos }\end{array}$ & $\$ 478500000$ & $\$ 507210000$ & $\$ 537642600$ & $\$ 672.804938$ & $\$ 785891908$ \\
\hline $\begin{array}{l}\text { Total egreso no } \\
\text { operacional }\end{array}$ & $\$ 62000000$ & $\$ 0$ & $\$ 0$ & $\$ 0$ & $\$ 0$ \\
\hline $\begin{array}{l}\text { Subtotal ingresos } \\
\text { financieros }\end{array}$ & $\$ 255000000$ & $\$ 0$ & $\$ 0$ & $\$ 0$ & $\$ 0$ \\
\hline $\begin{array}{l}\text { Total egresos } \\
\text { financieros }\end{array}$ & $\$ 29064346$ & $\$ 31706559$ & $\$ 2642213$ & $\$ 0$ & $\$ 0$ \\
\hline Total impuestos & $\$ 0$ & $\$ 62098759$ & $\$ 197480463$ & $\$ 1943452991$ & $\$ 4846246370$ \\
\hline $\begin{array}{l}\text { Caja del periodo } \\
\text { después de impuestos }\end{array}$ & $\$ 3778185$ & $\$ 649713112$ & $\$ 5707426072$ & $\$ 12743742071$ & $\$ 13721461722$ \\
\hline
\end{tabular}

Es importante observar que el proyecto presenta un estado de pérdidas y ganancias negativo, esto, por cuanto los costos de la operación son mayores a los ingresos percibidos. Este hecho genera un ahorro tributario para el segundo año por $\$ 62098759$. Como se ha indicado, al inicio el costo de gestión por crédito es alto, comparado con el ingreso por crédito; adicional a este hecho, las inversiones iniciales, asociadas al diseño y funcionamiento de la plataforma, son igualmente altas. Sin embargo, y bajo previsiones moderadas de crecimiento, el proyecto 
se recupera en los años siguientes y empieza a presentar flujos positivos de efectivo al final de cada periodo.

\section{Informes financieros}

A partir de los supuestos del proyecto (Anexo $G$ ), donde se han estimado unas variaciones de los costos de producción del 3,5\% anual, un incremento en los salarios del $6 \%$ anual y un crecimiento en ventas del $5 \%$ el primer año, $10 \%$ el segundo y $15 \%$ el tercero, se han construido los siguientes informes financieros. La tabla 3 presenta el estado de resultados del negocio proyectado a cinco años.

Tabla 3. Estado de resultados a 5 años

\begin{tabular}{llllll} 
& Año 1 & Año 2 & Año 3 & Año 4 & Año 5 \\
\hline+ Ventas & $\$ 318342530$ & $\$ 1126530912$ & $\$ 6445191348$ & $\$ 15360000000$ & $\$ 19353600000$
\end{tabular}

-Costo de ventas $\quad \$ 271500000 \quad \$ 287790.000 \quad \$ 305057400 \quad \$ 426264626 \quad \$ 524559177$

$=$ Utilidad Bruta $\quad \$ 46842530 \quad \$ 838740912 \quad \$ 6140133948 \quad \$ 14933735.374 \quad \$ 18829040823$

\begin{tabular}{|c|c|c|c|c|c|}
\hline $\begin{array}{l}\text {-Gastos de administración } \\
\text { y ventas }\end{array}$ & $\$ 207000000$ & $\$ 219420000$ & $\$ 232585200$ & $\$ 246540312$ & $\$ 261332731$ \\
\hline $\begin{array}{l}\text {-Depreciación y } \\
\text { amortización }\end{array}$ & $\$ 18266667$ & $\$ 18266667$ & $\$ 18266667$ & $\$ 1600000$ & $\$ 1600000$ \\
\hline$=$ Utilidad operacional & $-\$ 178424136$ & $\$ 601054245$ & $\$ 5889282082$ & $\$ 14685595062$ & $\$ 18566108092$ \\
\hline $\begin{array}{l}\text { +Ingresos no } \\
\text { operacionales }\end{array}$ & $\$ 0$ & $\$ 0$ & $\$ 0$ & $\$ 0$ & $\$ 0$ \\
\hline -Gastos no operacionales & $\$ 4000000$ & $\$ 0$ & $\$ 0$ & $\$ 0$ & $\$ 0$ \\
\hline -Gastos financieros & $\$ 5753923$ & $\$ 2628600$ & $\$ 30595$ & $\$ 0$ & $\$ 0$ \\
\hline $\begin{array}{l}=\text { Utilidad Antes de } \\
\text { impuestos }\end{array}$ & $-\$ 188178059$ & $\$ 598425645$ & $\$ 5889251487$ & $\$ 14685595062$ & $\$ 18566108092$ \\
\hline -Impuestos (33 \%) & $\$ 62098759$ & $\$ 197480463$ & $\$ 1943452991$ & $\$ 4846246370$ & $\$ 6126815670$ \\
\hline$=$ Utilidad neta & $-\$ 126079300$ & $\$ 400945182$ & $\$ 3945798496$ & $\$ 9839348691$ & $\$ 12439292422$ \\
\hline
\end{tabular}


Nota: Se presenta el Estado de Resultados del negocio proyectado a 5 años.

Este informe financiero ayuda a corroborar lo señalado anteriormente frente a los costos asociados a la operación durante el primer año. Nótese como el primer año el negocio presenta utilidades operacionales negativas, lo que obliga a financiar con recursos propios el funcionamiento de la empresa; sin embargo, en el segundo año se torna más eficiente, desde el punto de vista productivo, y empieza a arrojar utilidades operacionales positivas. Cabe señalar que, en el primer año y como consecuencia de la utilidad negativa, tenemos un saldo a favor en impuestos, es decir, se presenta un ahorro tributario, el cual disminuye el nivel de pérdidas de ese primer año y, como se observa en la tabla 2, ese ahorro se materializa en el flujo de caja del segundo año.

De otra parte, en la tabla 4 se puede observar que, a partir del segundo año, la utilidad neta crece de manera sostenida y a un muy buen ritmo, otorgando valor a la compañía, los socios y el proyecto.

Tabla 4. Estado de situación financiera a 5 años

\begin{tabular}{|c|c|c|c|c|c|c|}
\hline Activos & Inicio & Año 1 & Año 2 & Año 3 & Año 4 & Año 5 \\
\hline Caja y bancos & $\$ 255000000$ & $\$ 3778185$ & $\$ 653491297$ & $\$ 6360917369$ & $\$ 19104659440$ & $\$ 32826121162$ \\
\hline $\begin{array}{l}\text { Cuentas por } \\
\text { cobrar }\end{array}$ & & $\$ 0$ & $\$ 0$ & $\$ 0$ & $\$ 0$ & $\$ 0$ \\
\hline Inventario final & & $\$ 0$ & $\$ 0$ & $\$ 0$ & $\$ 0$ & $\$ 0$ \\
\hline $\begin{array}{l}\text { Total activo } \\
\text { corriente }\end{array}$ & $\$ 255000000$ & $\$ 3778185$ & $\$ 653491297$ & $\$ 6360917369$ & $\$ 19104659440$ & $\$ 32826121162$ \\
\hline Activos fijos & & $\$ 58000000$ & $\$ 58000000$ & $\$ 58000000$ & $\$ 58000000$ & $\$ 58000000$ \\
\hline $\begin{array}{l}\text { Depreciación } \\
\text { acumulada }\end{array}$ & & $\$ 18266667$ & $\$ 36533333$ & $\$ 54800000$ & $\$ 56400000$ & $\$ 58000000$ \\
\hline Activos fijos netos & & $\$ 39733333$ & $\$ 21466667$ & $\$ 3200000$ & $\$ 1600000$ & $\$ 0$ \\
\hline Total activos & $\$ 255000000$ & $\$ 43511518$ & $\$ 674957964$ & $\$ 6364117369$ & $\$ 19106259440$ & $\$ 32826121162$ \\
\hline
\end{tabular}

Pasivo y capital

Obligaciones

bancarias $\quad \$ 23310423 \quad \$ 29077959 \quad \$ 2611618 \quad \$ 0 \quad \$ 0$

Provisión

impuestos

$\$ 62098759 \$ 197480463 \$ 1943452991 \$ 4846246370$

$\$ 6126815670$

Total pasivos CP $\quad \$ 23310423 \quad \$ 33020801 \quad \$ 200092081 \quad \$ 1943452991 \quad \$ 4846246370 \quad \$ 6126815670$ 


\begin{tabular}{|c|c|c|c|c|c|c|}
\hline $\begin{array}{l}\text { Obligaciones } \\
\text { bancarias LP }\end{array}$ & $\$ 31689577$ & $\$ 2611618$ & $\$ 0$ & $\$ 0$ & $\$ 0$ & $\$ 0$ \\
\hline CxP LP & & $\$ 0$ & $\$ 0$ & $\$ 0$ & $\$ 0$ & $\$ 0$ \\
\hline Total pasivos Ip & $\$ 31689577$ & $\$ 2611618$ & \$0 & \$0 & $\$ 0$ & \$0 \\
\hline
\end{tabular}

\begin{tabular}{lrrrrrrr}
$\begin{array}{l}\text { Capital suscrito y } \\
\text { pagado }\end{array}$ & $\$ 200000000$ & $\$ 200000000$ & $\$ 200000000$ & $\$ 200000000$ & $\$ 200000000$ & $\$ 200000000$ \\
\hline $\begin{array}{l}\text { Pérdida/Utilidad } \\
\text { acumulada }\end{array}$ & $\$ 126079300$ & $\$ 274865883$ & $\$ 4220664379$ & $\$ 14060013070$ & $\$ 26499305492$ \\
\hline $\begin{array}{l}\text { Total patrimonio } \\
\text { \$200 000 000 }\end{array}$ & $\mathbf{\$ 7 3 9 2 0 7 0 0}$ & $\mathbf{\$ 4 7 4 8 6 5 8 8 3}$ & $\mathbf{\$ 4 4 2 0 6 6 4 3 7 9}$ & $\mathbf{\$ 1 4 2 6 0 0 1 3 0 7 0}$ & $\mathbf{\$ 2 6} 699305492$
\end{tabular}

Total pasivo y patrimonio
$\$ 255000000 \quad \$ 43511518 \quad \$ 674957964 \$ \$ 6364117369 \$ \$ 19106259440 \quad \$ 32826121162$

Cabe resaltar cómo el proyecto tiene la capacidad de reponerse a las pérdidas del primer año, logrando así un incremento en el patrimonio de la organización por encima de los \$26000 millones. Así mismo, se podrían esperar unos activos totales de más de \$32 000 millones, en su mayoría corrientes, lo que, evidentemente, puede apalancar el crecimiento futuro del negocio sin necesidad del endeudamiento externo, dada la disponibilidad de recursos propios para ello.

\section{Análisis de sensibilidad}

Para complementar el análisis del posible comportamiento financiero del proyecto, se han generado tres escenarios en los cuales se han afectado variables importantes para el funcionamiento del negocio y se miden los cambios en los ingresos, las utilidades operacionales y las utilidades netas.

\section{Escenario pesimista}

A partir del pronóstico más pesimista del comportamiento de la tasa de interés y del crecimiento de clientes se han desarrollado dos escenarios. El primero, que muestra la tabla 5 , presenta los resultados estimados en dos escenarios que se han considerado como pesimistas: 1) una tasa de interés de $2,7 \% \mathrm{MV}$; y 2) una tasa de crecimiento $5 \%$ inferior a la considera en las proyecciones.

Tabla 5. Resultados de escenarios pesimistas

\begin{tabular}{llllll}
$\begin{array}{l}\text { 2,7 \% MV Tasa de } \\
\text { interés }\end{array}$ & Año 1 & Año 2 & Año 3 & Año 4 & Año 5 \\
\hline Ventas & $\$ 268601510$ & $\$ 950510457$ & $\$ 5438130200$ & $\$ 15360000000$ & $\$ 19353600000$
\end{tabular}




\begin{tabular}{llllll} 
Utilidad operacional & $-\$ 228165157$ & $\$ 425033790$ & $\$ 4882220933$ & $\$ 14685595062$ & $\$ 18566108092$ \\
\hline Utilidad neta & $-\$ 159405783$ & $\$ 283011477$ & $\$ 3271067527$ & $\$ 9839348691$ & $\$ 12439292422$
\end{tabular}

\begin{tabular}{|c|c|c|c|c|c|}
\hline $\begin{array}{l}-5 \% \text { Tasa de } \\
\text { crecimiento }\end{array}$ & Año 1 & Año 2 & Año 3 & Año 4 & Año 5 \\
\hline Ventas & $\$ 183855965$ & $\$ 191116831$ & $\$ 342228463$ & $\$ 682881277$ & $\$ 1471627994$ \\
\hline Utilidad operacional & $-\$ 312910702$ & $-\$ 334359836$ & $-\$ 213680804$ & $\$ 8476339$ & $\$ 684136087$ \\
\hline Utilidad neta & $-\$ 216185298$ & $-\$ 225782252$ & $-\$ 143186637$ & $\$ 5679147$ & $\$ 458371178$ \\
\hline
\end{tabular}

Entre estos escenarios pesimistas, el que presenta un mayor efecto sobre las utilidades del proyecto es una tasa de crecimiento de nuevos clientes más baja que la esperada en el escenario moderado, manteniendo los demás elementos constantes. Es decir, se supone una tasa de crecimiento en el escenario moderado del $5 \%$, mientras que en el escenario pesimista esa tasa es del $-5 \%$ (decrecimiento).

Por otro lado, en el escenario pesimista, con una tasa del 2,7\% MV, más baja que la esperada en el escenario moderado (3,2 \% MV), se afectarían los niveles de utilidad del proyecto, pero se recuperaría rápidamente, logrando entrever que el proyecto tolera mejor las disminuciones de la tasa de interés que de las tasas de crecimiento de nuevos clientes.

\section{Escenario moderado}

A continuación, en la tabla 6 se presenta el resumen de los resultados de la simulación de la visión moderada, la cual fue usada como base para el diseño del presente plan de negocio, con una tasa de interés del 3,2\% MV y una tasa de crecimiento inicial del $5 \%$ anual.

Tabla 6. Resultados escenario moderado

\begin{tabular}{|c|c|c|c|c|c|}
\hline & Año 1 & Año 2 & Año 3 & Año 4 & Año 5 \\
\hline Ventas & $\$ 318342530$ & $\$ 1126530912$ & $\$ 6445191348$ & $\$ 15360000000$ & $\$ 19353600000$ \\
\hline Utilidad operacional & $-\$ 178424136$ & $\$ 601054245$ & $\$ 5889282082$ & $\$ 14685595062$ & $\$ 18566108092$ \\
\hline Utilidad neta & $-\$ 126079300$ & $\$ 400945182$ & $\$ 3945798496$ & $\$ 9839348691$ & $\$ 12439292422$ \\
\hline
\end{tabular}

Presenta los resultados proyectados bajo el escenario de planeación del proyecto. Tasa de interés del 3,2\% MV y una tasa de crecimiento inicial del $5 \%$ anual.

Como ya se ha señalado, este escenario se caracteriza por tener una tasa de crecimiento de nuevos clientes del $5 \%$ en el primer año, $10 \%$ el segundo, $15 \%$ el tercero, y crecer de manera vegetativa de ahí en adelante, a un ritmo del $5 \%$ anual. Los ingresos fueron 
calculados con el supuesto de una tasa de interés del 3,2 \% MV y una base de clientes inicial del $0,1 \%$ del total del mercado.

\section{Escenario optimista}

En esta simulación se busca determinar a cuál de las dos variables elegidas resulta ser más sensible el sistema. Para ello, nuevamente, consideramos dos escenarios donde una variable es alterada y todas las demás se mantienen constantes. Los principales efectos sobre las utilidades del proyecto ante un escenario optimista se relacionan en los resultados que se presentan en la tabla 7.

Tabla 7. Resultados del escenario optimista

\begin{tabular}{|c|c|c|c|c|c|}
\hline $\begin{array}{l}\text { 3,7 \% MV Tasa } \\
\text { de interés }\end{array}$ & Año 1 & Año 2 & Año 3 & Año 4 & Año 5 \\
\hline Ventas & $\$ 368083551$ & $\$ 1302551367$ & $\$ 7452252496$ & $\$ 15360000000$ & $\$ 19353600000$ \\
\hline $\begin{array}{l}\text { Utilidad } \\
\text { Operacional }\end{array}$ & $-\$ 128683116$ & $\$ 777074700$ & $\$ 6896343230$ & $\$ 14685595062$ & $\$ 18566108092$ \\
\hline Utilidad Neta & $-\$ 92752816$ & $\$ 518878887$ & $\$ 4620529465$ & $\$ 9839348691$ & $\$ 12439292422$ \\
\hline
\end{tabular}

\begin{tabular}{lllllll}
$\begin{array}{l}\text { 15 \% Tasa de } \\
\text { crecimiento }\end{array}$ & Año 1 & Año 2 & Año 3 & Año 4 & Año 5 \\
\hline Ventas & $\$ \mathbf{\$ 5 8 0 0 3 3 ~ 3 4 7}$ & $\$ \mathbf{\$ 6 1 8 7 2 3 7 9 9 9}$ & $\mathbf{\$ 1 0 1 1 8 6 9 2 0 2 7 1}$ & $\mathbf{\$ 3 0 7 2 0 0 0 0 0 0 0 0}$ & $\mathbf{\$ 3 8 7 0 7 2 0 0 0 0 0 0}$ \\
\hline $\begin{array}{l}\text { Utilidad } \\
\text { Operacional }\end{array}$ & $\$ 83266681$ & $\$ 5661761333$ & $\$ 100631011004$ & $\$ 306525595062$ & $\$ 386284508092$ \\
\hline Utilidad Neta & $\$ 49253548$ & $\$ 3791618931$ & $\$ 67422756874$ & $\$ 205372148691$ & $\$ 258810620422$ \\
\hline
\end{tabular}

Al definir el comportamiento de las utilidades bajo la alteración positiva de estas variables, se corrobora el hecho ya identificado en el escenario pesimista. El proyecto es más sensible a la variación de la tasa de crecimiento de los clientes que a variaciones en las tasas de interés, hecho que arroja elementos muy valiosos para el diseño y la gestión comercial, elementos de control de la compañía y el proyecto.

\section{Riesgos y supuestos críticos}

\section{Riesgos y supuestos}

A partir del análisis de sensibilidad, se pudo establecer que el proyecto presenta mayores alteraciones por cambios en la tasa de crecimiento de clientes. Así, entonces, un crecimiento más lento de créditos otorgados, en comparación con las expectativas moderadas, se consideraría crítico para la supervivencia del negocio, en especial por el hecho de que el 
primer año, debido a los altos costos de operación, el negocio genera rentabilidad negativa. Un crecimiento menor al esperado generaría una inviabilidad del negocio.

Por otro lado, si la tasa de crecimiento es mayor a la esperada, el negocio tendría rendimientos positivos durante el primer año, sin embargo, y dado que los capitales para el crédito son limitados, un crecimiento desmedido o demasiado rápido del mercado podría generar una insolvencia de capitales para el crédito, lo que podría ocasionar una demanda insatisfecha o una fracción del mercado a la espera de créditos sin poder ser atendido.

Así mismo, un incremento en la tasa de interés de los créditos aporta al mejoramiento del rendimiento del negocio, sin embargo, el umbral estaría dado por los precios de los créditos informales, pero es poco probable que, en un esquema legal, y bajo condiciones normales del mercado, las tasas de interés pudieran llegar a los niveles del crédito informal, es decir, por encima del $10 \% \mathrm{MA}$.

Por otro lado, la modernización y digitalización extrema de la banca tradicional sería un factor que, eventualmente, podría convertir en obsoleto el modelo de ABI, es decir, si la banca tradicional asimilara el modelo y lo escalara al nivel de su músculo financiero pondría en riesgo toda la estructura fintech de Colombia. Sin embargo, a partir del análisis del comportamiento de ese sector, es poco probable que en el corto plazo el esquema de digitalización de la banca tradicional iguale o equipare al de las nacientes fintech en Colombia.

Por último, se ha definido como una tasa de mora aceptable para el proyecto el 6,8\%. Cualquier tasa de mora en el pago de los créditos ocasiona riesgos para la operación y pérdidas en el ejercicio. Por ello, mantener la cartera con una mora inferior al $7 \%$ es fundamental para la salud, eficiencia financiera y éxito del proyecto.

Así mismo, se debe reconocer el hecho de que la estructura del plan de negocio de ABI, reposa sobre el supuesto de que las corporaciones o bancos de segundo nivel (Bancoldex, Finagro, Findeter, entre otras) estarían dispuestas a solventar los recursos de crédito para los microempresarios. Por lo tanto, un elemento vital para el negocio es la disposición y financiación por parte de esas entidades del fondo de crédito, ya que, si dicha financiación no se logra, o se toma más tiempo de lo planeado, el plan entra en una fase crítica que obliga a diseñar nuevas estrategias de fondeo para su actividad. Por esta razón, y planteando una alternativa como "Plan B", se debe considerar la posibilidad de buscar una inyección de capital en fondos privados (nacionales o internacionales), que tengan dentro de sus objetivos el fomento del desarrollo y crecimiento de la economía del sector microempresarial. De igual forma, y como estrategia de última instancia, se podría considerar la opción de abrir la capacidad de colocación de créditos a terceros o fondos de inversión en modalidad de socios. 


\section{Resultados e implicaciones}

Desarrollo económico: por la naturaleza de ABI, el mayor impacto del negocio se logrará en términos de desarrollo económico, debido a que este sistema digital de microcréditos es una apuesta frontal al desarrollo y crecimiento de la microempresa del país, al poner a su disposición recursos para inversión en capital de trabajo, con lo que se asegura el crecimiento del sector y, por ende, de la economía del país. Debido a que el crecimiento y la inversión de los negocios se financian bajo el crédito, $\mathrm{ABI}$ aportará de manera directa y decidida al desarrollo de la economía colombiana, como socio clave en el crecimiento de la microempresa nacional.

\section{Desarrollo de la comunidad}

ABI, por ser un sistema digitalizado de altísima penetración comercial, se convierte también en una herramienta de lucha directa contra los esquemas de crédito informal que tanto daño le han generado al país y la comunidad en general, al ser esos esquemas ilegales focos de violencia, angustia y estrés en las poblaciones víctimas de sus modalidades. Del mismo modo, al ser un esquema de crédito legal, digital bajo criterios de inclusión financiera, ABI tiene costos muchos más bajos que la alternativa ilegal, convirtiéndose en una alternativa cierta y probable para todas aquellas personas que requieren de capitales para financiar su actividad, manteniendo su capacidad de pago y con ello su tranquilidad.

Con ABI, se estaría apoyando el desarrollo empresarial, económico y familiar de miles de personas en todo el territorio nacional, pues dar soluciones efectivas y de bajo costo a los requerimientos de capitales para inversión a las microempresas es una estrategia directa de lucha contra la pobreza y en favor del desarrollo social y económico de la comunidad.

\section{Referencias}

Avendaño, J. (2019). Perspectivas del sector fintech para 2020 en Colombia y el mundo. Finance \& Investment Club Uniandes.

Bahamón, M. (2017). Un vistazo al panorama actual de las 'fintech' colombianas. Mesfix Blog.

Banca de las Oportunidades y Superintendencia Financiera de Colombia. (2017). Estudio de demanda de inclusión financiera. Informe de Resultados Segunda toma 2017. Banca de las Oportunidades y Superintendencia Financiera de Colombia. http://bancadelasoportunidades.gov.co/

BBC News Mundo. (7 de febrero de 2019). El suicidio por causa de un préstamo "gota a gota" que conmociona a Colombia. BBC News. 
Congreso de la República de Colombia. (2000, 10 de julio). Ley 590. Por la cual se dictan disposiciones para promover el desarrollo de las micro, pequeñas y medianas empresas. Diario Oficial 44078.

Congreso de la República de Colombia. (2004, 2 de agosto). Ley 905. Por medio de la cual se modifica la Ley 590 de 2000 sobre promoción del desarrollo de la micro, pequeña y mediana empresa colombiana y se dictan otras disposiciones. Diario Oficial 45628.

Economía Aplicada. ¿Cuántas empresas hay en Colombia? (27 de marzo de 2019). ¿Cuántas empresas hay en Colombia? Economía Aplicada.

El Tiempo. (3 de junio de 2015). En estratos 1 a 3, 73 \% de créditos los dan amigos. El Tiempo.

Guerrero, J. (1 de agosto de 2019). ¿Por qué el crédito informal ha crecido tanto? Finanzas Personales.

Hernández, E. y Oviedo, A. (2016). Mercado del crédito informal en Colombia: una aproximación empírica. Ensayos de Economía, 26(49), 137-156. https://revistas.unal.edu.co/index.php/ede/article/view/63820/59221

\section{Bibliografía consultada}

Fernández, F. (2017). Impacto de la informalidad laboral sobre el acceso a crédito formal. Coyuntura Económica, 47(1-2), 169-204. https://www.repository.fedesarrollo.org.co/handle/11445/3656

Iregui, A.; Melo, L.; Ramírez, M. y Tribín, A. (2016). Determinantes del acceso al crédito formal e informal: evidencia de los hogares de ingresos medios y bajos en Colombia. Banco de la República de Colombia. 


\section{ĆIF́F̂̉ 38}

\section{Anexos}

Anexo A. Diagrama de servicio de ABI

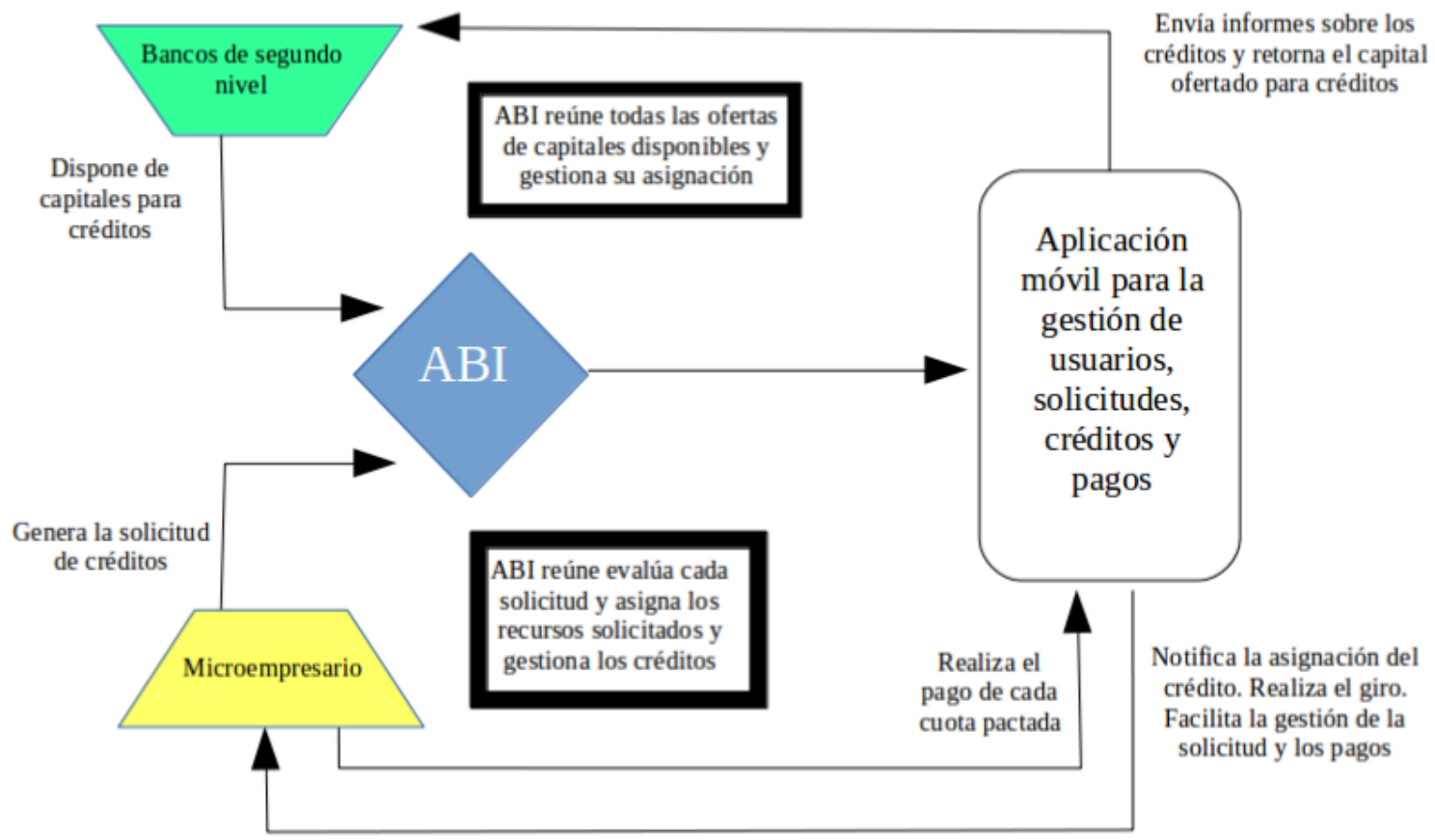

Anexo B. Prototipo 2: versión digital

Modelo de cuestionario en línea (descargado desde el servidor del repositorio del cuestionario)

\section{ABI-Microcréditos}

ABI es una plataforma de créditos para microempresarios. Por favor diligencie los datos para procesar su solicitud de crédito

Nombre ${ }^{* 1}$

Nombres y Apellidos completos

\section{Email $^{*}$}

Su número de celular*

Cuál es el monto del crédito solicitado*

- $\$ 200.000$

- $\$ 300.000$

\footnotetext{
1 *Información requerida.
} 


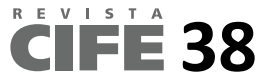

- $\$ 400.000$

- $\$ 500.000$

Fotografía del frente de su cédula

Fotografía del revés de su cédula

Fotografía de su rostro

Fotografía de su establecimiento o negocio

Anexo C. Matriz de análisis competitivo

\begin{tabular}{|c|c|c|c|c|c|}
\hline Factor & ABI & Fortaleza & Debilidad & Lineru & $\begin{array}{l}\text { Importancia para el } \\
\text { cliente }\end{array}$ \\
\hline Producto & $\begin{array}{l}\text { Crédito enfocado a } \\
\text { microempresarios. }\end{array}$ & $\begin{array}{l}\text { Segmento de } \\
\text { mercado definido } \\
\text { con una propuesta } \\
\text { de valor clara para } \\
\text { el segmento. }\end{array}$ & $\begin{array}{l}\text { Mercado limitado a } \\
\text { las características } \\
\text { de las necesidades } \\
\text { del crédito. }\end{array}$ & $\begin{array}{l}\text { Crédito para todo } \\
\text { tipo de personas. }\end{array}$ & $\begin{array}{l}\text { No es } \\
\text { relativamente } \\
\text { importante para el } \\
\text { cliente el enfoque } \\
\text { del crédito. }\end{array}$ \\
\hline Precio & $\begin{array}{l}\text { Tasa de interés por } \\
\text { debajo de la usura. }\end{array}$ & $\begin{array}{l}\text { No copex. } \\
\text { No capex. }\end{array}$ & $\begin{array}{l}\text { Se deben generar } \\
\text { otras formas de } \\
\text { financiar parte de } \\
\text { la operación. }\end{array}$ & $\begin{array}{l}\text { Tasa de interés } \\
\text { sobre el límite de } \\
\text { la usura más costos } \\
\text { de gestión. }\end{array}$ & $\begin{array}{l}\text { Este es un criterio } \\
\text { de elección del } \\
\text { cliente, es muy } \\
\text { importante. }\end{array}$ \\
\hline Servicio & $\begin{array}{l}\text { Virtual, de } \\
\text { respuesta rápida. }\end{array}$ & $\begin{array}{l}\text { Dentro de los } \\
\text { estándares actuales } \\
\text { de la industria. }\end{array}$ & & $\begin{array}{l}\text { Virtual, de } \\
\text { respuesta rápida. }\end{array}$ & $\begin{array}{l}\text { Interesa al cliente, } \\
\text { pero no le es muy } \\
\text { importante. }\end{array}$ \\
\hline
\end{tabular}

Anexo D. Relación de colaboradores

\begin{tabular}{|c|c|c|c|c|}
\hline Perfil & Tipo de trabajo & $\begin{array}{l}\text { Tipo de } \\
\text { contrato }\end{array}$ & $\begin{array}{l}\text { Requisitos de } \\
\text { formación }\end{array}$ & $\begin{array}{l}\text { Descripción del puesto de } \\
\text { trabajo }\end{array}$ \\
\hline $\begin{array}{l}\text { Ingeniero de } \\
\text { software }\end{array}$ & Profesional & Laboral & $\begin{array}{l}\text { Ingeniero de software, } \\
\text { de sistemas o afín, con } \\
\text { conocimientos en el } \\
\text { mantenimiento de } \\
\text { aplicaciones móviles. }\end{array}$ & $\begin{array}{l}\text { Actualizará y realizará el } \\
\text { mantenimiento de la } \\
\text { aplicación móvil, para } \\
\text { asegurar su correcto } \\
\text { funcionamiento en el tiempo y } \\
\text { su óptimo desempeño tanto } \\
\text { técnico como de seguridad. }\end{array}$ \\
\hline $\begin{array}{l}\text { Coordinador } \\
\text { comercial }\end{array}$ & Calificado & Laboral & $\begin{array}{l}\text { Coordinador y gestor } \\
\text { de grupos comerciales. }\end{array}$ & $\begin{array}{l}\text { Coordinar, diseñar y evaluar } \\
\text { la acción comercial y de venta } \\
\text { del servicio. }\end{array}$ \\
\hline
\end{tabular}




\begin{tabular}{|c|c|c|c|c|}
\hline Perfil & Tipo de trabajo & $\begin{array}{l}\text { Tipo de } \\
\text { contrato }\end{array}$ & $\begin{array}{l}\text { Requisitos de } \\
\text { formación }\end{array}$ & $\begin{array}{l}\text { Descripción del puesto de } \\
\text { trabajo }\end{array}$ \\
\hline Gerente general & $\begin{array}{l}\text { Profesional } \\
\text { especializado }\end{array}$ & Laboral & $\begin{array}{l}\text { Profesional con } \\
\text { experiencia en la } \\
\text { gestión de las } \\
\text { organizaciones y con } \\
\text { conocimiento del } \\
\text { sector de } \\
\text { microcréditos. }\end{array}$ & $\begin{array}{l}\text { Representar a la organización } \\
\text { y diseñar el plan estratégico } \\
\text { de la compañía. }\end{array}$ \\
\hline
\end{tabular}

\begin{tabular}{|c|c|c|c|c|}
\hline Marketing digital & Profesional & Laboral & $\begin{array}{l}\text { Persona con } \\
\text { capacidades y } \\
\text { conocimientos en el } \\
\text { manejo de las } \\
\text { herramientas y } \\
\text { estrategias SEO y SEl }\end{array}$ & $\begin{array}{l}\text { Lograr el posicionamiento del } \\
\text { servicio en el ambiente del } \\
\text { cliente y en los motores de } \\
\text { búsqueda empleando } \\
\text { herramientas digitales de SEM } \\
\text { y SEO. }\end{array}$ \\
\hline
\end{tabular}

\begin{tabular}{|c|c|c|c|c|}
\hline Contador & Profesional & Laboral & $\begin{array}{l}\text { Profesional con tarjeta } \\
\text { profesional y } \\
\text { formación como } \\
\text { contador. }\end{array}$ & $\begin{array}{l}\text { Registrar y llevar todos los } \\
\text { asientos contables de la } \\
\text { organización, presentar y } \\
\text { liquidar impuestos, } \\
\text { obligaciones, etc. }\end{array}$ \\
\hline
\end{tabular}

Ejecutivo comercial Técnico comercial Por corretaje o Técnico en ventas y Cumplir con las metas comisión comercialización de comerciales de venta, crear servicios, deseable con una base de datos de experiencia en potenciales clientes y servicios financieros. asistirlos, visitarlos y promover la venta con sus clientes. Gestionar la cartera de sus clientes.

Anexo E. Pronóstico de ventas

\begin{tabular}{llllll} 
& Año 1 & Año 2 & Año 3 & Año 4 & Año 5 \\
& Créditos & Créditos & Créditos & Créditos & Créditos \\
\hline M1 & 1250 & 2352 & 7716 & 39849 & 42000 \\
\hline M2 & 1313 & 2587 & 8874 & 40000 & 42000 \\
\hline M3 & 1378 & 2846 & 10205 & 40000 & 42000 \\
\hline M4 & 1447 & 3130 & 11736 & 40000 & 42000 \\
\hline M5 & 1519 & 3443 & 13496 & 40000 & 42000 \\
\hline M6 & 1595 & 3788 & 15521 & 40000 & 42000
\end{tabular}




\begin{tabular}{|c|c|c|c|c|c|}
\hline & Año 1 & Año 2 & Año 3 & Año 4 & Año 5 \\
\hline & Créditos & Créditos & Créditos & Créditos & Créditos \\
\hline M8 & 1759 & 4583 & 20526 & 40000 & 42000 \\
\hline M9 & 1847 & 5041 & 23605 & 40000 & 42000 \\
\hline M10 & 1939 & 5545 & 27146 & 40000 & 42000 \\
\hline M11 & 2036 & 6100 & 31217 & 40000 & 42000 \\
\hline M12 & 2138 & 6710 & 35900 & 40000 & 42000 \\
\hline $\begin{array}{l}\text { Tasa de } \\
\text { crecimiento }\end{array}$ & $5 \%$ & $10 \%$ & $15 \%$ & $11 \%$ & $5 \%$ \\
\hline Ticket promedio: & $\$ 500000$ & $\$ 700000$ & $\$ 900000$ & $\$ 1000000$ & $\$ 1200000$ \\
\hline Tasa interés: & $3,2 \% \mathrm{MV}$ & $3,2 \% \mathrm{MV}$ & $3,2 \% \mathrm{MV}$ & $3,2 \% \mathrm{MV}$ & $3,2 \% \mathrm{MV}$ \\
\hline Ingreso anual: & $\$ 318342530$ & $\$ 1126530912$ & $\$ 6445191348$ & $\$ 15360000000$ & $\$ 19353600000$ \\
\hline Anexo & F. Inversior & y gastos inic & ciales & & \\
\hline Activo & & Vida útil & Monto & Depreciación anual & \\
\hline Equipos de Con & nputación & 5 & $\$ 8000000$ & $\$ 1600000$ & \\
\hline Aplicación & & 3 & $\$ 50000000$ & $\$ 16666667$ & \\
\hline TOTAL & & & $\$ 58000000$ & $\$ 18266667$ & \\
\hline
\end{tabular}

\begin{tabular}{llll} 
Equipo de computación & Cantidad & Valor unitario & Valor total \\
\hline Computador & 2 & $\$ 2500000$ & $\$ 5000000$ \\
\hline Tabletas & 5 & $\$ 600000$ & $\$ 3000000$
\end{tabular}

\begin{tabular}{llll} 
Aplicación & Cantidad & Valor unitario & Valor total \\
\hline Diseño aplicación & 1 & $\$ 50000000$ & $\$ 50000000$
\end{tabular}

\begin{tabular}{lll} 
Gastos & Cantidad & Monto \\
\hline Registro de marca & 1 & $\$ 2000000$
\end{tabular}




\section{ĆIF́F̂̉ 38}

\begin{tabular}{lll} 
Gastos & Cantidad & Monto \\
\hline Registro de derechos de autor & 1 & $\$ 2000000$ \\
\hline Alojamiento Aplicación & 1 & $\$ 10500000$ \\
\hline Total & & $\$ 14500000$ \\
\hline Inversión inicial & $\$ \mathbf{\$ 7 2 5 0 0 0 0}$
\end{tabular}

\section{Anexo G. Supuestos financieros}

\section{Supuestos año 1}

\begin{tabular}{lcc} 
Ahorros / Equity / Patrimonio & $\$ 200000000$ \\
\hline Crédito & $\$ 55000000$ \\
Costo unitario adquisición por cliente & $\$ 1500$ \\
\hline Costo unitario gestión de crédito & $\$ 14564$ \\
\hline Inversión inicial & $\$ 72500000$ \\
\hline Aumento anual costo de producción & $3,5 \%$ \\
\hline Aumento anual salarios & $6 \%$ \\
\hline Ingreso por intereses & $\$ 318336000$ \\
\hline Impuesto de renta & $33 \%$ \\
\hline \# Crédito otorgados 1 año & 19896 \\
\hline Aumento anual de créditos otorgados & $10 \%$ \\
\hline & SA & SA \\
\hline
\end{tabular}

